Tropical Journal of Pharmaceutical Research September 2018; 17 (9): 1783-1788

ISSN: 1596-5996 (print); 1596-9827 (electronic)

(1) Pharmacotherapy Group, Faculty of Pharmacy, University of Benin, Benin City, 300001 Nigeria.

\title{
Effect of quercetin on biochemical parameters in letrozole- induced polycystic ovary syndrome in rats
}

\author{
Yanli Hong ${ }^{1}$, Yanyun Yin ${ }^{1}$, Yong Tan ${ }^{1}, K_{\text {Ke Hong }}{ }^{2}$, Fengrong Jiang ${ }^{2}$, Yao Wang ${ }^{3 *}$ \\ ${ }^{1}$ Department of Reproductive Medicine, ${ }^{2}$ Nanjing University of Chinese Medicine, ${ }^{3}$ Department of Laboratory Medicine, Affiliated \\ Hospital of Nanjing University of Traditional Chinese Medicine, Nanjing, Jiangsu 210000, China
}

*For correspondence: Email: yaowang42@hotmail.com; Tel: 0086-025-86617141

Sent for review: 20 February 2018

Revised accepted: 20 August 2018

\begin{abstract}
Purpose: To investigate the effect of quercetin, a natural flavonoid, on biochemical parameters in letrozole-induced polycystic ovary syndrome (PCOS) in rats

Methods: Oral glucose test was performed with the aid of a glucometer. Estradiol, testosterone and steroidogenic enzyme activities were determined using standard protocols. Superoxide dismutase (SOD), catalase (CAT) and glutathione peroxidase (GPX) activities were determined by standard methods. Histological analysis was carried out with haematoxylin and eosin (H\&E) staining.

Results: Quercetin exerted protective effects against PCOS in the rat model by enhancing the levels of antioxidant enzymes, viz, CAT, SOD and GPX. Quercetin also prevented weight gain, and caused significant decline in serum glucose levels in PCOS rats. Furthermore, quercetin normalised estradiol and testosterone levels, as well $t$ steroidogenic enzyme activities, but blocked letrozole-induced abnormalities in PCOS. It also exerted protective effects on the anatomy of the ovaries.

Conclusion: These results indicate that quercetin exerts protective effects on letrozole-induced PCOS in rats. Thus, quercetin may be an important lead molecule for the treatment of PCOS
\end{abstract}

Keywords: Letrozole, Quercetin, Polycystic ovary syndrome, Oxidative stress, Steroidogenic enzymes

\begin{abstract}
This is an Open Access article that uses a funding model which does not charge readers or their institutions for access and distributed under the terms of the Creative Commons Attribution License (http://creativecommons.org/licenses/by/4.0) and the Budapest Open Access Initiative (http://www.budapestopenaccessinitiative.org/read), which permit unrestricted use, distribution, and reproduction in any medium, provided the original work is properly credited.
\end{abstract}

Tropical Journal of Pharmaceutical Research is indexed by Science Citation Index (SciSearch), Scopus, International Pharmaceutical Abstract, Chemical Abstracts, Embase, Index Copernicus, EBSCO, African Index Medicus, JournalSeek, Journal Citation Reports/Science Edition, Directory of Open Access Journals (DOAJ), African Journal Online, Bioline International, Open-J-Gate and Pharmacy Abstracts

\section{INTRODUCTION}

Polycystic ovary syndrome (PCOS) is one of the prevalent types of endocrine abnormalities that affect 4 to $10 \%$ of women of reproductive age $[1,2]$. Generally, PCOS is characterised by hyper-androgenism, insulin insensitivity and oligo-ovulation [3]. Studies over the last few decades have confirmed that PCOS is often associated with enhanced risk of type 2 diabetes [4]. It has been reported that women with mild form of PCOS which is associated with slight hyper-androgenism and normal ovulation, are prone to PCOS later in life [5]. In PCOS, enhanced androgen activity often affects the gonadotropin-triggered estrogen and progesterone biosynthesis in follicles [6].

Currently available treatment strategies for PCOS are based on the use of metformin and other insulin sensitizers [7]. However, these drugs are associated with several side effects which worsen the quality of lives of patients [8]. Therefore, there is a need to develop alternative 
treatment strategies for PCOS. Against this background, many studies have focused on the screening of natural products for their potential in the management of PCOS, based on the fact that they have much lower side effects than synthetic drugs. Flavonoids comprise a large group of plant secondary metabolites with tremendous pharmacological potential [9]. Quercetin is an important flavonoid with antidiabetic activity. Studies have shown that quercetin, in combination with other flavonoids, exhibited hypoglycaemic activity in a type 2 diabetes rat model [10]. The present study was carried out to investigate the effect of quercetin on some biochemical parameters in letrozoleinduced PCOS in rats.

\section{EXPERIMENTAL}

\section{Animals}

Virgin female Sprague-Dawley rats (mean weight $=90 \pm 5 \mathrm{~g}$ ) were used in this study. Vaginal cytological analysis was carried out daily to monitor the four day ovarian cycle. The animals were maintained under standard conditions with appropriate light and temperature, and were given free access to drinking water and feed. They were randomly divided into four groups: group I received $1 \%$ $\mathrm{CMC}$ only, while group II received $1 \% \mathrm{CMC}$ plus $25 \mathrm{mg}$ quercetin/ $\mathrm{kg}$ body weight. Rats in group III received $1 \mathrm{mg}$ letrozole/kg only, while group IV rats were given the same dose of letrozole along with $25 \mathrm{mg}$ quercetin $/ \mathrm{kg}$ body weight. The PCOS was induced by administration of letrozole (1 $\mathrm{mg} / \mathrm{kg}$ body weight) once daily for 21 days.

At the end of the study, the animals were sacrificed under deep isoflurane anaesthesia, and the ovaries were excised for further studies. For histological studies, one of the ovaries was fixed in Bouins fluid and the second ovary was used for the assays of steroidogenic enzyme activities. The study was approved by the Animal Ethics Committee of Nanjing University of Chinese Medicine (Approval No. NUCM/EA/7065 of 2017).The international guidelines for animal studies were strictly complied with all through the investigations [11].

\section{Oral glucose tolerance test (OGT) and determination of steroidal hormone concentration}

The rats were fasted continuously for $12 \mathrm{~h}$ prior to the end of treatments. They were then fed with glucose $(300 \mathrm{mg} / \mathrm{kg} / \mathrm{body}$ weight), and then oral glucose test (OGT) was carried out as described previously [12]. Blood was collected at $30 \mathrm{~min}$ intervals for 120 min from the tail vein of each rat. The blood samples were subjected to blood glucose determination using a glucometer. Blood levels of testosterone and estradiol were determined using methods descried previously [13].

Preparation of ovarian homogenate and assay of steroidogenic enzyme activities

Tris- $\mathrm{HCl}$ buffer $(0.1 \mathrm{M}, \mathrm{pH} 7.8)$ was used to prepare $10 \%$ ovarian homogenate. The homogenate was then centrifuged at $8000 \mathrm{~g}$ for 1 $h$, and the supernatant was used for estimation of protein content and steroidogenic enzymes.

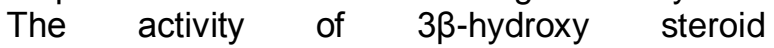

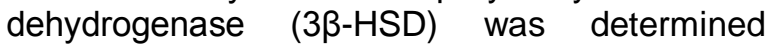
spectrophotometrically in terms of nanomoles of $\mathrm{NADH}$ produced $/ \mathrm{min} / \mathrm{mg}$ protein [14l. The activity of $17 \beta-H S D$ was estimated as described previously, and the activity was expressed as nanomoles of $\mathrm{NADPH}$ oxidized $/ \mathrm{min} / \mathrm{mg}$ protein [15].

\section{Determination of enzymatic antioxidants}

Superoxide dismutase (SOD) was determined with the method of Kakkar et al [16].Catalase activity was determined as described by Whanger et al [17], while glutathione peroxidase (GPX) activity was assayed according to the method outlined by Paglia and Valentine [18].

\section{Histological examination of ovaries}

The ovary samples were fixed in Bouins fixative and used for histological analysis in accordance with standard procedures. Sections (5- $\mu \mathrm{m}$ thick) were cut from paraffin-embedded tissue and stained with haematoxylin and eosin ( $H$ \& $E)$ prior to examination under the microscope.

\section{Statistical analysis}

All experiments were carried out in triplicate and data are presented as mean \pm SD. Statistical analysis was done using one-way analysis of variance (ANOVA), followed Tukey's test. All analyses were done with GraphPad 7 software. Values of $p<0.01$ and $<0.05$ were considered significant.

\section{RESULTS} Effect of quercetin on body weight
andoestrous cycle of PCOS rats

Administration of letrozole continuously for 21 days caused significant increases in body weights of the rats, relative to rats in the control 
(Figure 1). However, quercetin administration caused significant decreases in the body weights of the PCOS rats (group IV), when compared to rats given letrozole alone (group III). PCOS rats (Group III) showed prolonged dioestrous stage, but this was reversed by exposure to quercetin (25 mg/kg), making it less prolonged compared to PCOS rats. However, there was no difference between group I and group II with respect to the time of dioestrous stage.

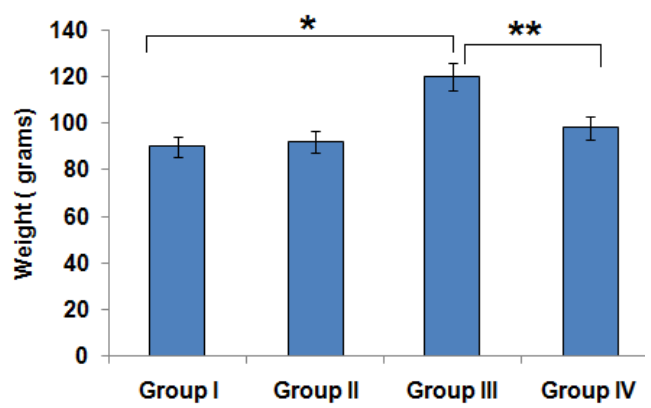

Figure 1: Effect of quercetin on the weight of rats in the different groups. The experiments were carried out in triplicate and values are presented as mean \pm SD $\left({ }^{*} p<0.01,{ }^{* *} p<0.05\right)$

\section{Effect of quercetin on plasma glucose levels}

There was no significant difference in plasma glucose levels between group I and group II rats. However, administration of quercetin $(25 \mathrm{mg} / \mathrm{kg})$ to the letrozole-treated rats (group IV) resulted in reduction in plasma glucose levels, when compared to the rats administered letrozole only (group III; Figure 2).

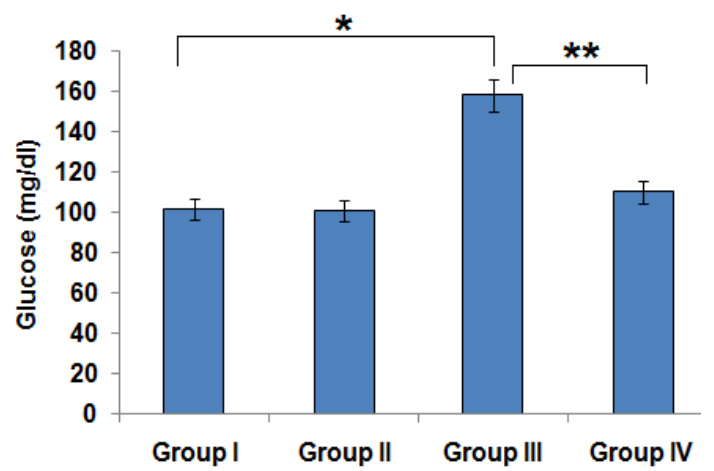

Figure 2: Effect of quercetin on the plasma glucose levels of mice in the different groups. The experiments were carried out in triplicates, and the values are presented as mean $\pm \mathrm{SD}\left({ }^{*} p<0.01,{ }^{* *} p<0.05\right)$

\section{Effect of quercetin on testosterone and estradiol levels}

The testosterone levels of rats given letrozole were significantly increased, but were reduced by quercetin administration $(25 \mathrm{mg} / \mathrm{kg}$ body weight.
However, no significant difference was found in testosterone concentrations between group I and group II rats (Figure $3 \mathrm{~A}$ ). Similar effects were observed with estradiol levels (Figure $3 \mathrm{~B}$ ).

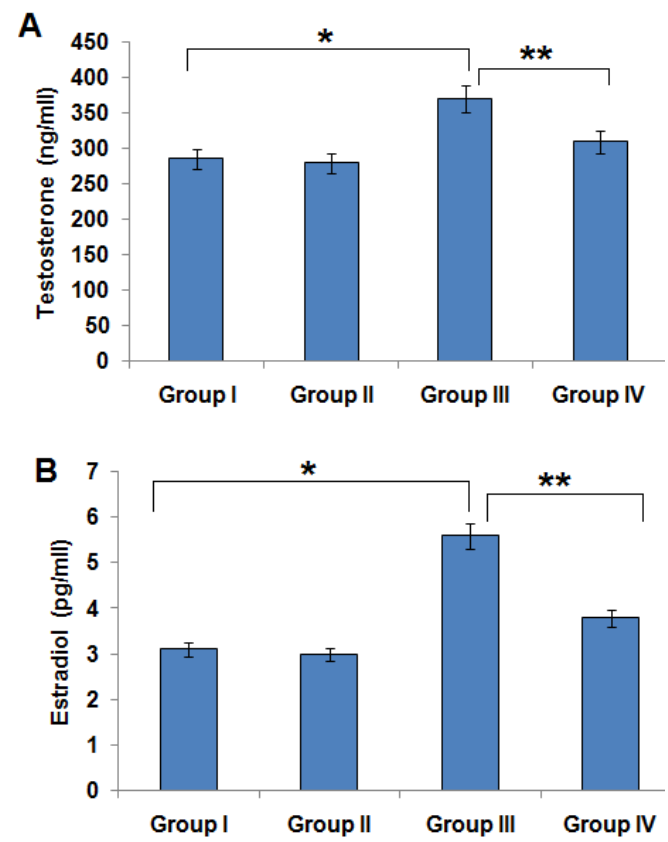

Figure 3: Effect of quercetin on (A) testosterone, and (B) estradiol in the different groups. The experiments were carried out in triplicates. Values are presented as mean $\pm \operatorname{SD}\left({ }^{*} p<0.01,{ }^{* *} p<0.05\right)$

\section{Effect of quercetin on steroidogenic enzymes}

In the letrozole-only group (PCOS, Group III), there were significant increases in the activities of $3 \beta-H S D$ and $17 \beta-H S D$, relative to the controls (group I and group II). However, administration of quercetin at $25 \mathrm{mg} / \mathrm{kg}$ body weight to the PCOS rats (group IV) provoked significant decreases in the levels of $3 \beta$-HSD and $17 \beta-H S D$ (Figure 4).

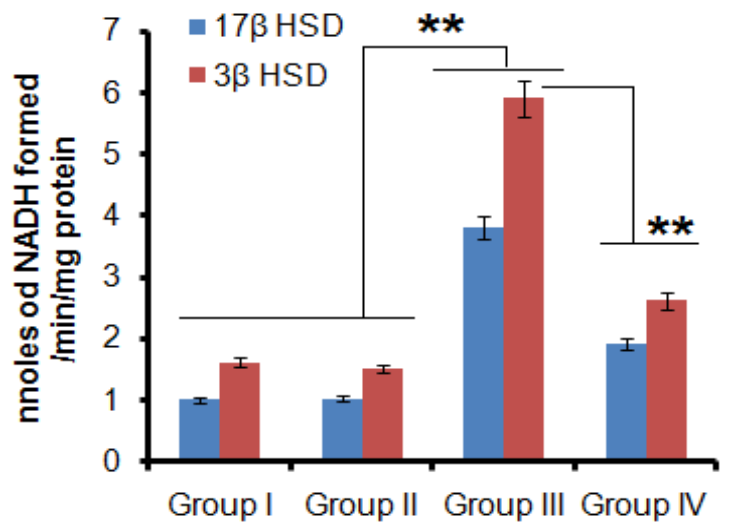

Figure 4: Effect of quercetin on steroidogenic enzyme activities in the different groups. The experiments were carried out in triplicate, and the results are presented as mean $\pm \mathrm{SD}\left({ }^{\star} p<0.01,{ }^{* \star} p<0.05\right)$ 


\section{Effect of quercetin on antioxidant enzyme levels}

The activities of SOD, CAT and GPX were significantly decreased in PCOS rats, when compared with the control groups (group I and group II). However, quercetin administration reversed the letrozole-induced decreases in the activities of these enzymes (Figure $5 \mathrm{~A}-\mathrm{C}$ ).

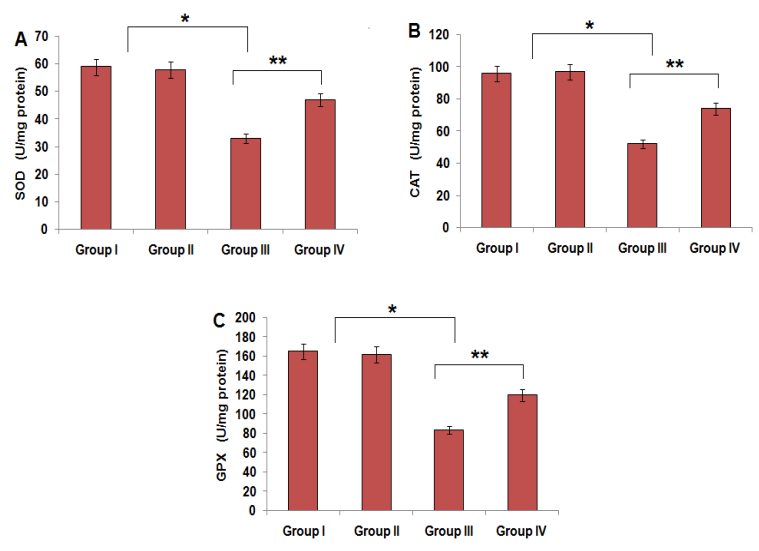

Figure 5: Effect of quercetin on the activities of (A) SOD, (B) CAT,and (C) GPX in rats in the different groups. The experiments were carried out in triplicate, and the results are presented as mean $\pm \mathrm{SD}\left({ }^{*} p<\right.$ $0.01,{ }^{* *} p<0.05$ )

\section{Histological features}

The control rats (groups I and II) exhibited normal ovary architecture, but the PCOS rats (group III) showed follicular cysts, reduced granulose cell layers, and hyperplasia. However administration of quercetin to the PCOS rats (group IV) restored normal ovary anatomy appreciably (Figure 6).
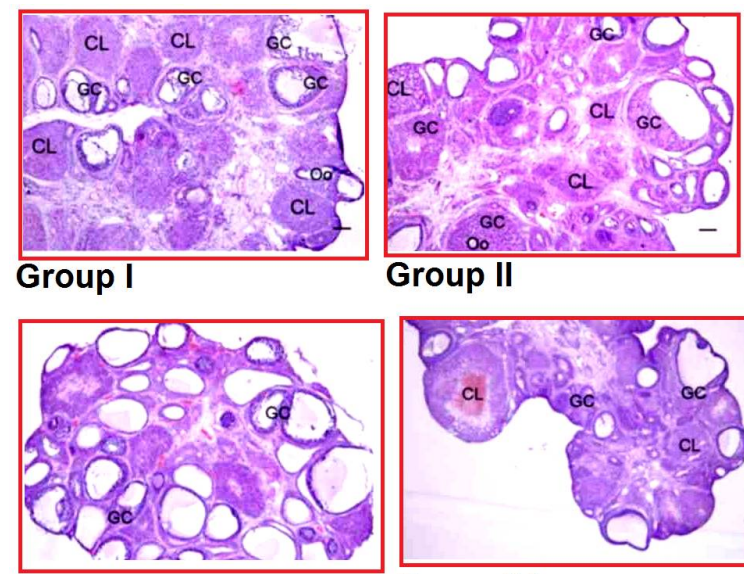

Group III

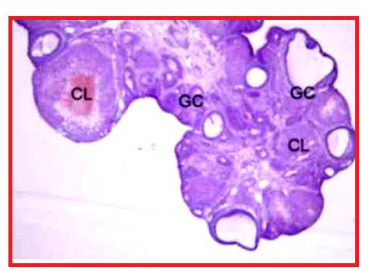

Group IV

Figure 6: Effect of quercetin on histopathology of rat ovaries in the different groups (H\&E). (GC: granulosa cell, Oo: oocyte, CL: corpus luteum)

\section{DISCUSSION}

The exact cause of PCOS is still not clear. Nonetheless, it is believed to be a genetic disorder associated with abnormal production of gonadotropin, enhanced production of steroidogenic enzymes, insensitivity to insulin, oligo-ovulation, as well as irregular menstruation which often lead to sub-fertility [2]. Currently, PCOS is treated mainly by administration of insulin sensitizers. However, these treatments have lots of side effects which necessitate the development of alternative treatment options for better management of the disease [3].

Plant products have long been considered as rich sources of drugs. In fact, a number of currently used drugs come from plants. Plants produce diverse metabolites that exhibit capacities to interact with wide array of cellular molecules such as enzymes [19]. Among plant secondary metabolites, flavonoids form a very diverse and large group. They have been reported to exhibit beneficial pharmacological potential [20]. Moreover, flavonoids are prevalently found in edible plants and are generally considered safe for human consumption [21].

Recently, it was reported that soy flavonoids exerted protective effects against letrozoleinduced PCOS in rats [22]. Given this background, the effect of quercetin, one of the strong antioxidant flavonoids, in a letrozoleinduced PCOS rat model was investigated in the present study. It was observed that quercetin prevented weight gain associated with PCOS, and reduced serum glucose levels in PCOS rats. These results are in agreement with those from previous studies wherein quercetin was reported to exhibit hypoglycaemic effects in diabetic rats [23].

Quercetin decreased the activities of the steroidogenic enzymes (3ß-HSD and/or $17 \beta$ HSD) in the PCO rat model. This could possibly be due to the presence of the phenolic ring $B$ in quercetin [24]. It has been reported that this flavonoid ring exhibits the capacity to inhibit $3 \beta$ HSD and/or 17 $\beta$-HSD. Quercetin also decreased the levels of testosterone and estradiol in PCOS. Oxidative stress has been reported as the main pathological characteristic of PCOS in women [1]. In the present study, evaluation of the effect of quercetin on the antioxidant enzymes revealed that quercetin significantly increased the activities of SOD, CAT and GPX in PCOS rat model, and also reversed the effects of letrozole on ovarian morphology. 


\section{CONCLUSION}

These results indicate that quercetin exerts protective effects on letrozole-induced PCOS. Thus, quercetin has a promising potential for use in the management of PCOS in women.

\section{DECLARATIONS}

\section{Acknowledgement}

This study was supported by Natural Science Foundation of Jiangsu Province of China (no. BK20151006); University Excellent Science and Technology Innovation Team of Jiangsu Province of China; and Chinese Hospitals Fund Projects of Jiangsu Province of China (no. Y17024).

\section{Conflict of interest}

No conflict of interest is associated with this work.

\section{Contribution of authors}

The authors declare that this work was done by the authors named in this article and all liabilities pertaining to claims relating to the content of this article will be borne by them. Yanli Hong, Yanyun Yin, Yong Tan performed all of the experiments. Ke Hong and Fengrong Jiang gave assistance during revision. This study was designed and under supervision of Yao Wang.

\section{REFERENCES}

1. Franks S. Polycystic ovary syndrome. New England J Med. 1995; 333(13): 853-861.

2. Knochenhauer ES, Key TJ, Kahsar-Miller M, Waggoner $W$, Boots $L R$ and Azziz R. Prevalence of the polycystic ovary syndrome in unselected black and white women of the southeastern United States: a prospective study. $J$ Clin Endocrinol Metabol 1998; 83(9): 3078-3082.

3. Dunaif $A$. Insulin resistance and the polycystic ovary syndrome: mechanism and implications for pathogenesis. Endocrine Rev 1997; 18: 774-800.

4. Ehrmann DA, Barnes RB, Rosenfield RL, Cavaghan MK and Imperial J. Prevalence of impaired glucose tolerance and diabetes in women with polycystic ovary syndrome. Diabetes care 1999; 22(1): 141-146.

5. Fr DD and Tarlatzis R. Revised 2003 consensus on diagnostic criteria and long-term health risks related to polycystic ovary syndrome. Fertility and Sterility 2004; 81: 1-7.

6. Apridonidze T, Essah PA, luorno MJ and Nestler JE. Prevalence and characteristics of the metabolic syndrome in women with polycystic ovary syndrome. $J$ Clin Endocrinol Metabol 2005; 90(4): 1929-1935.

7. Legro RS, Finegood D, Dunaif $A$. A fasting glucose to insulin ratio is a useful measure of insulin sensitivity in women with polycystic ovary syndrome. J Clin Endocrinol Metabol 1998; 83(8): 2694-2698.

8. Kiddy DS, Hamilton-Fairley D, Bush A, Short F, Anyaoku $V$, Reed MJ and Franks S. Improvement in endocrine and ovarian function during dietary treatment of obese women with polycystic ovary syndrome. Clin Endocrinol 1992; 36(1): 105-111.

9. Formica JV and Regelson W. Review of the biology of quercetin and related bioflavonoids. Food Chemical Toxicol 1995; 33(12): 1061-1080.

10. Vessal $M$, Hemmati $M$ and Vasei $M$. Antidiabetic effects of quercetin in streptozocin-induced diabetic rats. Toxicol Pharmacol 2003; 135: 357-364.

11. McGrath JC, Drummond GB, McLachlan EM, Kilkenny C and Wainwright CL. Guidelines for reporting experiments involving animals: the ARRIVE guidelines. Br J Pharmacol 2010; 160(7): 1573-1576.

12. Goto $Y$, Kakizaki $M$ and Masaki N. Production of spontaneous diabetic rats by repetition of selective breeding. Tohoku J Exp Med 1976; 119(1): 85-90.

13. Fink HA, Ewing SK, Ensrud KE, Barrett-Connor E, Taylor $B C$, Cauley JA and Orwoll ES, Osteoporotic Fractures in Men Study Group. Association of testosterone and estradiol deficiency with osteoporosis and rapid bone loss in older men. J Clin Endocrinol Metabol 2006; 91(10): 3908-3915.

14. Steckelbroeck S, Jin, Y, Gopishetty, S, Oyesanmi Ba and Penning TM, 2004. Human Cytosolic 3a-Hydroxysteroid Dehydrogenases of the Aldo-keto Reductase Superfamily Display Significant $3 \beta$-Hydroxysteroid Dehydrogenase Activity: implications for steroid hormone metabolism and action. J Biol Chem 2004; 279(11): 10784-10795.

15. Vierikko $P$, Kauppila $A$, Rönnberg $L$ and Vihko $R$. Steroidal regulation of endometriosis tissue: lack of induction of $17 \beta$-hydroxysteroid dehydrogenase activity by progesterone, medroxyprogesterone acetate, or danazol. Fertil Steril 1985; 43(2): 218-224.

16. Kakkar P, Das $B$ and Viswanathan PN. A modified spectrophotometric assay of superoxide dismutase. Indian J Biochem Biophys 1984; 21: 130-132

17. Kaplan JH and Groves JN. Liver and blood cell catalase activity of tumor-bearing mice. Cancer Res 1972; 32(6): 1190-4.

18. Whanger $P D$, Beilstein $M A$, Thomson $C D$, Robinson $M F$ and Howe M. Blood selenium and glutathione peroxidase activity of populations in New Zealand, Oregon, and South Dakota. FASEB J 1988; 2(14): 29963002.

19. Schmidt T, Khalid S, Romanha A, Alves T, Biavatti M, Brun R, Da Costa F, de Castro S, Ferreira $V$, de Lacerda $M$ et al., The potential of secondary metabolites from plants as drugs or leads against protozoan 
Hong et al

neglected diseases-part II. Curr Med Chem 2012; 19(14): 2176-228.

20. Havsteen B. Flavonoids, a class of natural products of high pharmacological potency. Biochem Pharmacol 1983; 32(7):1141-1148.

21. Chun OK, Chung SJ and Song WO. Estimated dietary flavonoid intake and major food sources of US adults. $J$ Nutr 2007; 137(5): 1244-1252.

22. Rajan RK and Balaji B. Soy isoflavones exert beneficial effects on letrozole-induced rat polycystic ovary syndrome (PCOS) model through anti-androgenic mechanism. Pharm Biol 2017; 55(1): 242-251.

23. Kamalakkannan $N$ and Prince PS. Antihyperglycaemic and antioxidant effect of rutin, a polyphenolic flavonoid, in streptozotocin-induced diabetic wistar rats. Basic Clin Pharmacol Toxicol 2006; 98(1): 97-103.

24. Pietta PG. Flavonoids as antioxidants. J Nat Prod 2000; 63(7): 1035-1042. 